Article

\title{
Optimization of Inventory Routing Problem in Refined Oil Logistics with the Perspective of Carbon Tax
}

\author{
Songyi Wang ${ }^{1}$, Fengming Tao ${ }^{1,2, *}$ and Yuhe Shi ${ }^{3}$ \\ 1 College of Mechanical Engineering, Chongqing University, Chongqing 400044, China; \\ songyi_wang@cqu.edu.cn \\ 2 School of Economics and Business Administration, Chongqing University, Chongqing 400044, China \\ 3 School of Transportation and Logistics, Southwest Jiaotong University, Chengdu 610031, China; \\ SHI681242@163.com \\ * Correspondence: taofengming@cqu.edu.cn; Tel.: +86-185-8070-7012
}

Received: 12 May 2018; Accepted: 28 May 2018; Published: 4 June 2018

\begin{abstract}
In order to solve the optimization problem of the refined oil distribution system from the perspectives of low-carbon and environmental protection, this paper focuses on the characteristics of the secondary distribution of refined oil and combines it with the integrated optimization concept of refined oil distribution network, where a low-carbon inventory routing problem (LCIRP) model is constructed with the minimum total costs as the objective function on the basis of considering carbon emissions. An adaptive genetic algorithm combined with greedy algorithm is designed to solve the model, and an example is given to verify the effectiveness of the algorithm. Then, this paper solves the model with two parts by introducing a practical numerical example: in the first part, the LCIRP models with different carbon tax values are solved, which verifies the effectiveness of the model and proves that carbon tax policies can effectively reduce the carbon emissions in the secondary distribution network of refined oil; in the second part, the LCIRP models with the different maximum load capacity of oil tank trucks are solved, which provides the economic and environmentally friendly distribution schemes for refined oil distribution enterprises under the premise of carbon tax policies and load limitation. Finally, the emission reduction proposals that take into account both economic and environmental benefits are given respectively from the aspect of government environmental protection agencies and from the aspect of refined oil distribution enterprises.
\end{abstract}

Keywords: refined oil distribution; inventory routing problem; hybrid genetic algorithm; carbon emissions; carbon tax

\section{Introduction}

As a special energy commodity, petroleum plays a decisive role in the national economy and people's livelihood in a country [1]. The distribution of refined oil refers to the entire logistics process of transporting refined oil from the oil refinery to consumers, which connects the oil refining company, distribution oil depots and sales outlets (gas stations). In addition, the distribution of refined oil can be divided into two stages: primary distribution and secondary distribution. A primary distribution refers to the process of transporting refined oil from the refinery to distribution oil depots, and secondary distribution refers to the process of transporting refined oil from a distribution oil depot to gas stations [2]. The secondary distribution of refined oil has the characteristics of small quantity and multiple batches. With the intensification of global market competition, the importance and necessity of a highly efficient distribution network integration strategy have begun to become prominent. How to achieve the reduction of transportation costs and the improvement of distribution efficiency in the 
inventory routing problem (IRP) of gas stations in a region has gradually become a core problem in corporate distribution management. At the same time, the combinatorial optimization research on the IRP of refined oil secondary distribution has also become the focus of many scholars.

In order to meet the needs of economic development, gas stations need a continuous supply of refined oil, but the transport of small quantity and multiple batches poses a series of threats to the ecological environment. The transportation of petrochemical products will generate a large amount of carbon emissions, which will lead to the increase of greenhouse gases, exacerbating air pollution and the greenhouse effect [3,4]. With the continuous promulgation of the carbon tax and other regulatory policies, the low-carbon transportation is imperative [5]. Therefore, it is necessary to optimize the design of the refined oil distribution network while considering the constraints of efficiency and environment, thus reaching a balanced state of economic efficiency and environmental benefits to achieve a win-win situation.

The remaining parts of this paper are organized as follows. In the next section, a literature review on the refined oil distribution optimization problem, as well as the balance between carbon reduction and cost optimization, is presented. Section 3 discusses the construction of the low-carbon IRP (LCIRP) model. The hybrid genetic algorithm is introduced to solve the model in Section 4. Section 5 gives a numerical experiment and results analysis. Finally, Section 6 concludes this paper and presents expectations for future work.

\section{Literature Review}

Since the main idea of the current research is to balance carbon emission reduction and cost optimization in IRP of refined oil logistics. We review the studies in two fields: refined oil distribution optimization and the balance between carbon reduction and cost optimization.

\subsection{Refined Oil Distribution Optimization}

Federgruen and Zipkin [6] first explicitly proposed the inventory routing problem (IRP) in 1984. They optimized the inventory routing scheme of the supply chain through scientifically making decisions about retailer's order quantity, order cycle, and route arrangement. In the same period, Golden et al. [7] also made a similar study. The ratio of the current inventory level to the storage capacity was used to describe the urgency of distribution demands, and a heuristic algorithm was designed to solve the problem.

With the improvement of the research level, the research of IRP has shown a trend of increasing complexity of the problem, and the depth and breadth of the problem have been extended. Avella et al. [8] studied the oil transportation problem with limited distribution resources (limited vehicles and limited drivers). A heuristic algorithm combined with the branch pricing algorithm was designed, which can be solved quickly. Moreover, they illustrated the effectiveness of the algorithm by multiple sets of real-world examples. Cornillier et al. [9-11] has been devoted to the study of IRP. They constructed mathematical models from the perspectives of multi-period distribution, distribution with time windows, multiple oil depot distribution and so on, and designed efficient algorithms to solve them. For the vehicle routing problem in the distribution of refined oil, Dai et al. [12] designed a human-computer interactively solving method based on a two-phase heuristic algorithm. Ma et al. [13] proposed a mathematical model with the shortest driving path and high full load rate as the optimization goals for the secondary distribution of refined oil, and the improved genetic algorithm was used to solve the model. Bocto et al. [14] designed several heuristic algorithms to solve the mathematical model for the problem of replenishment at gas stations, the simulation and real data were applied to verify the effectiveness of the algorithms respectively. Zhen et al. [15] studied the distribution of refined oil from the perspective of third-party logistics and introduced a combinatorial auction mechanism to construct a mixed-integer programming model with the objective of minimizing costs. A heuristic algorithm was devised to solve the problem. Popovic et al. [16] aimed at IRP in the refined oil logistics. An improved variable neighborhood search algorithm was introduced to solve the 
joint optimization model of the inventory and routing. In the case of known distribution routes and limited number of vehicles, Li et al. [2] introduced the concept of order neighborhood into refined oil distribution and established the optimization model of refined oil distribution route based on order neighborhood. The model was solved by an improved quantum genetic algorithm. Wang et al. [17] divided the secondary distribution of refined oil into two modes: one claimed that the different oil products required by a gas station was permitted to be separated and distributed by several vehicles, and the other must be entirely delivered by one single vehicle. According to the two modes, two kinds of distribution sub-models were derived on the basis of the basic model of the product oil multi-cabin distribution with time window, and they proposed an ant colony and tabu search hybrid algorithm (ACO-TS) to solve models.

\subsection{The Balance between Carbon Emission Reduction and Cost Optimization}

Environmental protection has been an issue of serious concern for many years [18]. In the perspectives of carbon tax and other series of carbon policies, many scholars pay attention to the trade-off between costs and carbon emissions in the optimization of low-carbon logistics.

Jabali et al. [19] studied the trade-off between carbon emissions and travel time in time-dependent vehicle routing problems and discussed the boundaries of carbon emissions in transportation. Elhedhli et al. [20] embedded carbon emission costs into the design costs of supply chain network, in which the calculation of carbon emissions was modeled by considering the vehicle weight. The test results indicate that the design scheme of supply chain network considering the carbon emission costs will has a great change. Wang et al. [21] proposed a multi-objective optimization model for the network design of green supply chain. The economic costs and carbon emissions in the network design of supply chain were taken into account, and the choice of facility location and transportation mode were determined by the intensity of emission reduction. Tsai et al. [22] presented a mixed activity-based costing decision model for green airline fleet planning. They analyzed the impact of carbon emissions on operating costs of aviation logistics under the constraints of the European Union Emissions Trading Scheme. Jaber et al. [23] studied the cooperation between buyers and sellers based on minimizing carbon emissions, and numerical analysis showed that carbon tax was a very effective way to control carbon emissions. The impacts of carbon regulatory mechanisms on replenishment decisions in a biofuel supply chain were analyzed by Palak et al. [24]. They employed the mathematical models to capture the trade-offs that exist between costs and emissions due to inventory and transportation.

In short, based on the above two parts of the analysis, there are many studies on combination optimization in refined oil logistics. At the same time, the research on the optimization design of low-carbon supply chains is abundant under carbon tax and other regulatory policies. However, there is no research on the low carbonation of IRP in refined oil logistics. In the existing refined oil logistics researches, whether it is the basic IRP or the variant problem of IRP, most of them only aim at the optimization of operating costs and rarely consider carbon emissions. However, with the gradual deepening of the concept of sustainable development and the implementation of a number of energy-saving and emission reduction policies, carbon emission in the optimization of refined oil distribution network has become a problem to be solved urgently. In view of this, this paper proposes a green and environmental protection model that considers carbon emissions in the optimization of refined oil logistics networks: the low-carbon inventory routing problem (LCIRP) model. An adaptive genetic algorithm combined with greedy algorithm is designed to solve the model. Finally, the effectiveness and feasibility of the model are verified by numerical experiments. 


\section{Model Formulation}

\subsection{Problem Description}

The LCIRP model of refined oil distribution studied in this paper can be described as follows. An oil depot distributes refined oil to different gas stations through oil tank trucks. The location of each gas station is known, and a limited number of oil tank trucks start from the oil depot and return after the distribution tasks have been completed. Based on meeting the inventory requirements of gas stations and the constraint of the trucks load, the LCIRP model with the minimum comprehensive costs is constructed by considering the fixed costs, transportation costs, shortage costs, inventory costs, penalty costs, and carbon emission costs in the distribution process. Then, we hope to obtain the economic and environmental-friendly distribution plan under the premise of ensuring the delivery services are completed.

\subsection{Parameters and Variables}

According to the needs of building the model, this paper sets the following parameters and variables, as shown in Table 1.

Table 1. The meaning of parameters and variables.

\begin{tabular}{|c|c|}
\hline $\begin{array}{l}\text { Parameters } \\
\text { and Variables }\end{array}$ & Meaning \\
\hline$V$ & $\begin{array}{l}\text { The collection of nodes, } 1,2, \ldots, V \text { is the serial number of gas stations, } 0 \text { represents oil depot, } \\
V\{n|n=0,1,2, \ldots,| V \mid\}\end{array}$ \\
\hline K & The collection of oil tank trucks owned by oil depot, $K\{k|k=1,2, \ldots| K \mid\}$, \\
\hline$I_{0}$ & The initial inventory of oil depot \\
\hline$R$ & The actual amount of completed delivery of the oil depot \\
\hline$h_{0}$ & The inventory rates of oil depot (the inventory costs of unit cargoes for unit time) \\
\hline$M$ & The fixed cost of using the oil depot \\
\hline$C_{0}$ & The carbon tax on unit carbon emissions \\
\hline$Q_{k}$ & The maximum load allowed for oil tank truck $k$ \\
\hline$v$ & The speed of oil tank trucks \\
\hline$r_{i}$ & The demand of gas station $i$ \\
\hline$c_{i j}^{k}$ & The transportation costs for unit distance when the oil tank truck $k$ from node $i$ to node $j$ \\
\hline$h_{i}$ & The inventory rates of gas station $i, h_{0}<h_{i}$ \\
\hline$C_{k}$ & The fixed cost of oil tank truck $k$ \\
\hline$\mu_{1}$ & The waiting costs for unit time when the oil tank truck arrives at gas station node in advance \\
\hline$\mu_{2}$ & The penalty costs for unit time when the oil tank truck is late to gas station node \\
\hline$Q_{i j}^{k}$ & The weight of the loaded cargoes when the oil tank truck $k$ travels between node $i$ and node $j$ \\
\hline$t_{s i}$ & The time required for oil tank trucks to serve gas station $i$ \\
\hline$d_{i j}$ & The transport distance from node $i$ to node $j$ \\
\hline$t_{i j}^{k}$ & The travel time of oil tank truck $k$ from node $i$ to node $j$ \\
\hline$t_{i}^{k}$ & The time to arrive at the node $i$ for oil tank truck $k$ \\
\hline$b_{i}$ & The unit shortage cost for gas station $i$ \\
\hline$I_{i}$ & The inventory of gas station $i$ after distribution \\
\hline$C M$ & The carbon emissions from oil tank truck during the distribution process \\
\hline$\left[E T_{i}, L T_{i}\right]$ & Time window required by gas station $i$ (namely, the range of time) \\
\hline$\rho$ & The fuel consumption of oil tank truck for unit distance \\
\hline$\rho_{0}$ & The fuel consumption for unit distance when oil tank truck is empty \\
\hline$e_{0}$ & The carbon emissions generated by unit fuel consumption \\
\hline$\rho^{*}$ & The fuel consumption for unit distance when oil tank truck is fully loaded \\
\hline$Y_{k}$ & $Y_{k}=1$ represents oil tank truck $k$ is used in oil depot, otherwise $Y_{k}=0$ \\
\hline$y_{i}^{k}$ & $y_{i}^{k}=1$ represents the oil tank truck $k$ serves the gas station $i$, otherwise $y_{i}^{k}=0$ \\
\hline$x_{i j}^{k}$ & $\begin{array}{l}x_{i j}^{k}=1 \text { represents the oil tank truck } k \text { passes through the road between node } i \text { and node } j, \\
\text { otherwise } x_{i j}^{k}=0\end{array}$ \\
\hline
\end{tabular}




\subsection{Model Development}

The LCIRP model of refined oil distribution constructed in this paper takes the total costs minimum as the objective function. Firstly, we need to analyze the sub-costs, and then the total costs of the IRP are determined by the various sub-costs.

\subsubsection{Objective Function Analysis of Model}

\section{Fixed Costs}

The fixed costs $C_{1}$ in the LCIRP model can be expressed as

$$
C_{1}=M+\sum_{k \in K} C_{k} Y_{k}
$$

where $C_{1}$ contains the fixed costs of using oil depots and oil tank trucks, which mainly includes routine maintenance, depreciation expenses as well as labor costs for drivers and other employees.

\section{Transportation Costs}

Under the influence of fuel consumption, maintenance and other factors, the transportation costs are proportional to the travel mileage of the trucks. The transportation $\operatorname{costs} C_{2}$ in the LCIRP model can be expressed as

$$
C_{2}=\sum_{k \in K} \sum_{i, j \in V} c_{i j}^{k} x_{i j}^{k} d_{i j} Y_{k}
$$

\section{Shortage Costs}

The shortage costs of gas stations are proportional to the shortage volume in the current period.

$$
C_{3}=b_{i} \max \left\{0, r_{i}-I_{i}\right\}
$$

\section{Penalty Costs}

When sudden events such as urban traffic jam, trucks breakdown and other emergencies occur, oil tank trucks may be unable to reach the destination within the time range required by gas stations (affected by inventory capacity and safety inventory of the gas stations, refined oil need to be sent to gas stations between the earliest delivery time and the latest delivery time). If oil tank trucks cannot arrive on time, it is necessary to pay a certain amount of penalty costs $C_{4}$.

$$
C_{4}=\sum_{k \in K} \sum_{i \in V \backslash\{0\}}\left(\mu_{1} \max \left\{E T_{i}-t_{i}^{k}, 0\right\}+\mu_{2} \max \left\{t_{i}^{k}-L T_{i}, 0\right\}\right)
$$

where $\max \left\{E T_{i}-t_{j}^{k}, 0\right\}$ indicates the advance arrival time for oil tank truck $k$ services gas station $i$; $\max \left\{t_{i}^{k}-L T_{i}, 0\right\}$ indicates the late time for oil tank truck $k$ services gas station $i$.

5. Inventory Costs

Distribution activity occurs at the end of each distribution cycle and before the start of next cycle. The inventory costs of oil depot can be expressed as:

$$
H_{0}=h_{0}\left(I_{0}-R\right), R=\sum_{i \in V \backslash\{0\}}\left(r_{i} \sum_{j \in V} x_{i j}^{k}\right)
$$


Due to the different inventory between the beginning of the delivery cycle and the end of the delivery cycle, the average inventory is used to calculate the inventory costs of the gas station $i$, which is denoted by $H_{i}$.

$$
H_{i}=h_{i}\left(I_{i}-\frac{1}{2} \min \left\{r_{i}, I_{i}\right\}\right)
$$

The inventory costs $C_{5}$ consist of two parts: the inventory costs of oil depot and the inventory costs of the gas station.

$$
C_{5}=h_{0}\left(I_{0}-\sum_{i \in V \backslash\{0\}}\left(r_{i} \sum_{j \in V} x_{i j}^{k}\right)\right)+\sum_{i \in V \backslash\{0\}} h_{i}\left(I_{i}-\frac{1}{2} \min \left\{r_{i}, I_{i}\right\}\right)
$$

\section{Carbon Emission Costs}

Carbon emissions during the distribution and transportation process of refined oil are mainly caused by fuel consumption.

The linear function formula of fuel consumption in per unit distance $\rho(X)$ is introduced in this paper.

$$
\rho(X)=\rho_{0}+\frac{\rho^{*}-\rho_{0}}{Q} X
$$

Therefore, the carbon emissions can be expressed as follows:

$$
C M=e_{0} \rho\left(Q_{i j}^{k}\right) d_{i j},\left(0 \leq Q_{i j}^{k} \leq Q_{k}\right)
$$

The carbon emission costs of the LCIRP model $C_{6}$ shown as follows:

$$
C_{6}=C_{0} \sum_{k \in K} \sum_{i \in V} \sum_{j \in V} x_{i j}^{k} d_{i j}\left[e_{0} \rho\left(Q_{i j}^{k}\right)\right]
$$

\subsubsection{LCIRP Model Setting}

Based on the analysis in Section 3.3.1, the LCIRP model of refined oil distribution constructed in this paper is as follows:

$$
\begin{aligned}
\min C= & \left(M+\sum_{k \in K} C_{k} Y_{k}\right)+\left(\sum_{k \in K} \sum_{i, j \in V} c_{i j}^{k} x_{i j}^{k} d_{i j} Y_{k}\right) \\
& +\left(b_{i} \max \left\{0, r_{i}-I_{i}\right\}\right) \\
& +\left(\sum_{k \in K} \sum_{i \in V \backslash\{0\}}\left(\mu_{1} \max \left\{E T_{i}-t_{i}^{k}, 0\right\}+\mu_{2} \max \left\{t_{i}^{k}-L T_{i}, 0\right\}\right)\right) \\
& +h_{0}\left(I_{0}-\sum_{i \in V \backslash\{0\}}\left(r_{i} \sum_{j \in V} x_{i j}^{k}\right)\right)+\sum_{i \in V \backslash\{0\}} h_{i}\left(I_{i}-\frac{1}{2} \min \left\{r_{i}, I_{i}\right\}\right) \\
& +C_{0} \sum_{k \in K} \sum_{i \in V} \sum_{j \in V} x_{i j}^{k} d_{i j}\left[e_{0} \rho\left(Q_{i j}^{k}\right)\right]
\end{aligned}
$$

Subject to

$$
\begin{gathered}
\sum_{k \in K} \sum_{j \in V \backslash\{0\}} x_{i j}^{k}=1, \forall i \in V \\
\sum_{i \in V} x_{i j}^{k}=\sum_{i \in V} x_{j i}^{k}, \forall j \in V \backslash\{0\} \\
\sum_{j \in V\{0\}} x_{0 j}^{k}=\sum_{i \in V \backslash\{0\}} x_{i 0}^{k}=1, \forall k \in K
\end{gathered}
$$




$$
\begin{gathered}
\sum_{i \in V \backslash\{0\}}\left(r_{i} \sum_{j \in V} x_{i j}^{k}\right) \leq I_{0}, \forall k \in K \\
Q_{i j}^{k} \leq Q_{k} x_{i j}^{k}, i \neq j, \forall i \in V, \forall j \in V, \forall k \in K \\
x_{i j}^{k}+x_{j i}^{k} \leq 1, \forall i \in V \backslash\{0\}, \forall j \in V \backslash\{0\}, \forall k \in K \\
t_{j}^{k}=t_{i}^{k}+t_{s i}+t_{i j}^{k}, \forall i \in V, \forall j \in V, \forall k \in K
\end{gathered}
$$

The objective function of the model is to minimize the total costs, as shown in (11). Constraint (12) imposes the attention that there is only one oil tank truck provides delivery service for each gas station. Constraint (13) indicates the balance of oil tank trucks that entering and leaving each gas station. All oil tank trucks start from the oil depot and return to the oil depot after the distribution tasks are completed, and their operation is shown in (14). Constraint (15) represents that the delivery volume is limited by the remaining stock of the oil depot. Furthermore, the delivery volume is limited by the loading capacity of oil tank truck, as mentioned in (16). Constraint (17) is introduced to eliminate the sub-loops. The continuity of the travel time of oil tank trucks is emphasized in (18).

\section{Algorithm Design}

Genetic algorithm is a random parallel search algorithm based on the principles of natural selection and genetics, which is a more effective method for solving NP-Hard problem [25,26]. However, traditional genetic algorithm often has the disadvantages of slow convergence rate, easy falling into local optimum, and low optimization accuracy. Therefore, the goal of the continuous improvement of genetic algorithm is how to improve the convergence rate of the algorithm while ensuring the diversity of population, so that the optimization result is close to the optimal solution. In this paper, we propose an improved adaptive genetic algorithm combined with greedy algorithm (Hybrid Genetic Algorithm, HGA) to solve the LCIRP model. The following improvements have been made based on traditional genetic algorithms.

\subsection{Combining Greedy Algorithm to Generate Initial Population}

In traditional genetic algorithm, the initial population that is generated by a stochastic method has a low individual fitness, which will restrict the convergence rate of the algorithm to a certain extent. The greedy algorithm is used to optimize the initial individuals in this paper, which means the advantage of greedy algorithm in local optimization is utilized to generate new individuals. First, we select a gas station randomly and add it into individual. Then, the nearest gas station to the current gas station should be found through searching for all gas stations that have not been added to the individual, and it will be added into the individual as the current location. The initially optimized individual can be got by continuing searching the nearest gas station until all gas stations are added into the individual. The initial population generated by the greedy algorithm does not lose randomness, and its overall quality is improved, which helps to bring higher optimization speed. After we get the initial population, what we need to do is optimizing each initial individual by the genetic algorithm. In each iteration process, the fitness of the individuals should be calculated at first, and then the selection, crossover, and mutation operations are performed in sequence.

\subsection{Adaptive Adjustment Mechanism of Crossover Probability}

In the evolution of the traditional genetic algorithm, crossover probability $p_{c}$ and mutation probability $p_{m}$ are often set to fixed numbers [27]. However, parameters such as $p_{c}$ and $p_{m}$ are the key factors that affect the performance of the genetic algorithm [28]. Many researches have studied the adaptive calculation of parameters such as crossover probability and mutation probability of the genetic algorithm $[27,29-31]$. On the basis of these, the adaptive adjustment mechanisms are set up for $p_{c}$ and $p_{m}$ in this paper. 
Crossover operation promotes the continuous updating of the population, and the size of $p_{c}$ determines the updating rate of individuals. If the $p_{c}$ is too large, it will destroy the excellent genetic modes. If the $p_{c}$ is too small, the search speed of the algorithm will be slow, and the population will be difficult to evolve. In the early stages of evolution, in order to expand the overall search range and increase the updating speed of population, the value of $p_{c}$ should be increased. In the later stages of evolution, the overall solution set of population tends to be stable, so $p_{c}$ should be appropriately reduced to keep the superior gene structures preserved. In addition, the crossover operator can change or even destroy the gene structures. For individuals with poor fitness, it should be set higher $p_{c}$ because more participation in crossover operation is benefit to its continuous optimization. Correspondingly, for individuals with higher fitness, the probability of crossover operation should be smaller in order to prevent the destruction of the gene structures. Based on the above analysis, we set the following adjustment mechanisms:

$$
\begin{gathered}
p_{c i}=\left\{\begin{array}{c}
\max p_{c}-\left(\max p_{c}-\min p_{c}\right)\left(\frac{g}{2 G}+\frac{f_{i}-\bar{f}}{2\left(f_{\max }-\bar{f}\right)}\right), f_{i} \geq \bar{f} ; \\
\max p_{c}, f_{i}<\bar{f} .
\end{array}\right. \\
\max p_{c}=\left\{\begin{array}{c}
0.9, g \leq G / 4 \\
0.8, G / 4<g \leq 3 G / 4 \\
0.7,3 G / 4<g \leq G .
\end{array}\right.
\end{gathered}
$$

where $p_{c i}$ is the probability that crossover operation occurs on the individual $i$, a higher crossover probability is given in the early evolution and the crossover probability is decreased in the later stages of evolution; $G$ is the maximum iteration number during evolution; $g$ is the current iteration number; the value of $\max p_{c}$ is related to the current iteration number, $\min p_{c}=0.6$; $f_{i}$ is the fitness of individual $i, f_{\max }$ is the maximum fitness value of all individuals, and $\bar{f}$ is the average fitness value of the current population.

\subsection{Adaptive Adjustment Mechanism of Mutation Probability}

The mutation of population will be affected by $p_{m}$, and the proper mutation of individuals can maintain the diversity of the population and prevent it from falling into a local optimum. However, if $p_{m}$ is too large, the algorithm is similar to random search and loses the characteristic of genetic evolution. From the two aspects of genetic evolution number and the fitness values of individuals, an adjusting formula for mutation probability is established.

$$
p_{m i}=\left\{\begin{array}{c}
\min p_{m}+\left(\max p_{m}-\min p_{m}\right)\left(\frac{g}{2 G}+\frac{f_{i}-\bar{f}}{2\left(f_{\max }-\bar{f}\right)}\right), f_{i} \geq \bar{f} \\
\min p_{m}, f_{i}<\bar{f}
\end{array}\right.
$$

where $p_{m i}$ is the probability that mutation occurs on the individual $i$. From the Formula (21), it can be seen that the smaller the fitness values of individuals, the less the possibility of mutation. With the increase in the iteration number, individuals tend to have a similar genetic structure, which is likely to fall into a local optimum. In order to avoid this situation, the mutation probability of individuals should be appropriately increased to encourage the emergence of new individuals and maintain individuals' diversity. We set $\max p_{m}=0.005, \min p_{m}$ has been adjusted with the change of iteration number, which is shown as follows:

$$
\min p_{m}=\left\{\begin{array}{c}
0.001, g \leq G / 4 \\
0.002, G / 4<g \leq 3 G / 4 \\
0.003,3 G / 4<g \leq G
\end{array}\right.
$$


In the early stages of evolution, individuals are less likely to occur mutation; in the later stages of evolution, the higher mutation probability of individuals is conducive to expanding the search scope and jumping out of local optimum.

Based on the above analysis, the basic process of the improved algorithm designed in this paper is illustrated in Figure 1.

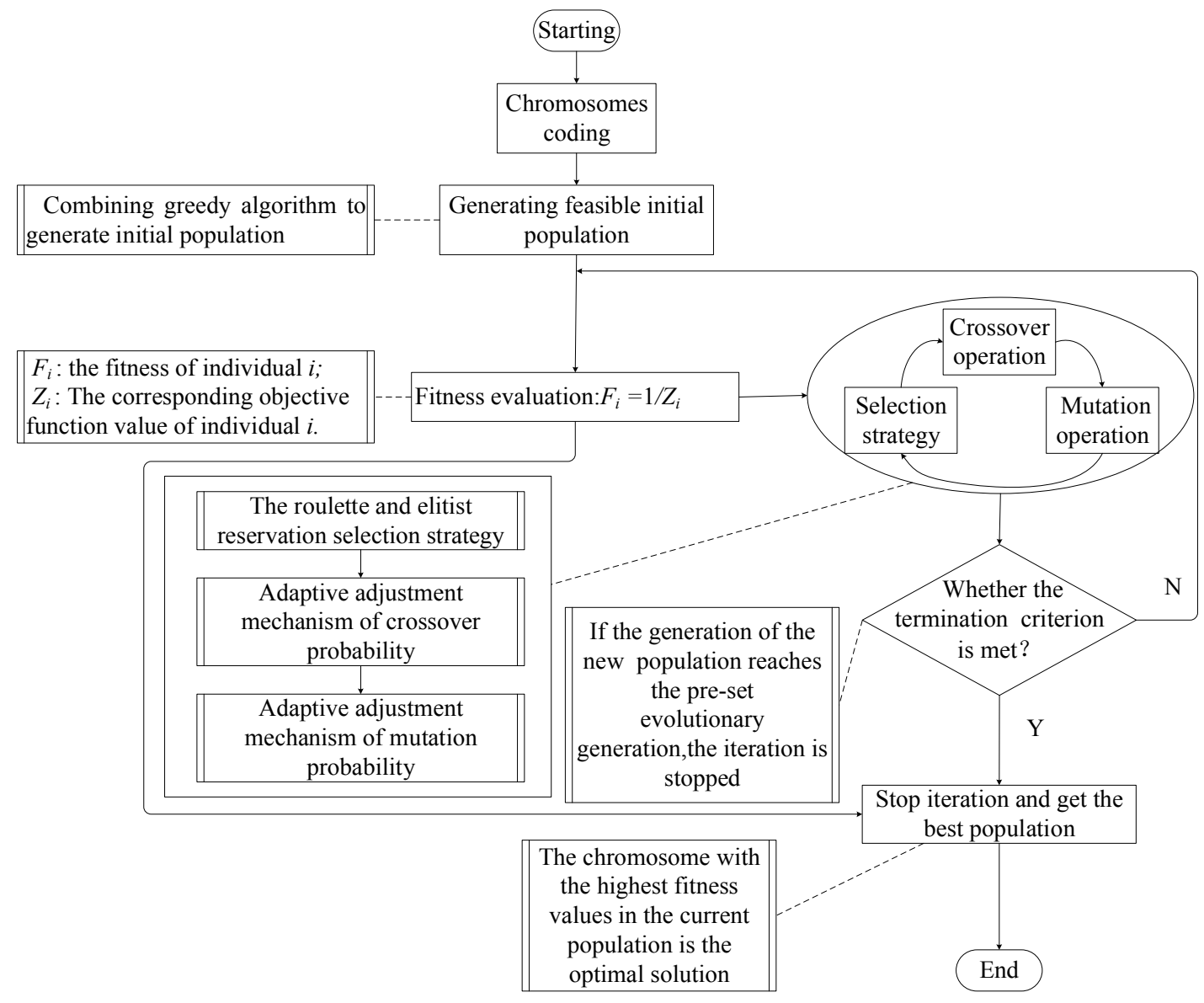

Figure 1. Basic process of hybrid genetic algorithm.

\section{Experimental Design and Result Analysis}

The example verification includes two parts: First, the HGA proposed in this paper is tested in Section 5.1 by using the typical VRP test question database. Second, in Section 5.2, the effectiveness of the LCIRP model is verified by an actual example of distribution problem in a refined oil logistics enterprise.

\subsection{Algorithm Experiment}

In this section, the typical test question database that is called Benchmark Problems [32] is used to verify the effectiveness of the proposed HGA. There are six test examples listed in the test question database (that is, $\mathrm{R} 1, \mathrm{C} 1, \mathrm{RC} 1, \mathrm{R} 2, \mathrm{C} 2$, and RC2), and this paper randomly selects two problems from each type of examples to form test data sets, which are solved by the traditional genetic algorithm (GA), the cycle evolutionary genetic algorithm (CEGA) [5], and HGA proposed in this paper. The results are shown in Table 2. 
Table 2. Experimental results of HGA and other algorithms.

\begin{tabular}{|c|c|c|c|c|c|c|}
\hline \multirow{2}{*}{ Examples } & \multicolumn{2}{|l|}{ GA } & \multicolumn{2}{|l|}{ CEGA } & \multicolumn{2}{|l|}{ HGA } \\
\hline & The Number of Trucks & Distance & The Number of Trucks & Distance & The Number of Trucks & Distance \\
\hline R1-01 & 19 & 1701.92 & 18 & 1647.32 & 18 & 1613.56 \\
\hline $\mathrm{R} 1-12$ & 9 & 996.31 & 9 & 982.14 & 9 & 983.68 \\
\hline C1-04 & 10 & 881.23 & 10 & 831.58 & 10 & 824.78 \\
\hline C1-05 & 10 & 879.37 & 10 & 828.94 & 10 & 828.94 \\
\hline RC1-01 & 14 & 1789.36 & 14 & 1696.94 & 14 & 1634.29 \\
\hline RC1-08 & 10 & 1396.51 & 10 & 1139.82 & 10 & 1139.82 \\
\hline R2-02 & 6 & 1242.34 & 3 & 1191.70 & 4 & 1176.39 \\
\hline $\mathrm{R} 2-10$ & 4 & 1137.54 & 3 & 939.34 & 3 & 939.34 \\
\hline C2-01 & 3 & 643.57 & 3 & 591.56 & 3 & 591.56 \\
\hline C2-06 & 4 & 685.43 & 4 & 654.91 & 3 & 588.49 \\
\hline RC2-05 & 5 & 1517.68 & 4 & 1389.37 & 4 & 1297.19 \\
\hline RC2-07 & 4 & 1259.31 & 3 & 1061.14 & 3 & 1061.14 \\
\hline
\end{tabular}

As can be seen from Table 2, when solving the above 12 examples, the results obtained by HGA are $100 \%$ better than the results obtained by GA, and nearly $91.7 \%$ are better than the results obtained by CEGA. Therefore, the HGA proposed in this paper is very competitive in solving the test examples.

\subsection{Model Experiment}

In this paper, the data of the refined oil distribution from an oil transportation company (hereinafter referred to as OTC) are introduced to verify the LCIRP model. The OTC needs to transport the refined oil in the oil depot to gas stations. The initial stock of the oil depot is 20 thousand cubic meters, and the oil depot coordinates are $(54,41)$. The demand for refined oil at 19 gas stations in a certain area should be met by the oil depot, the location of the gas stations and the information of the inventory and demand are shown in Table 3. All distribution tasks are carried out by road transportation, and all roads are non-forbidden roads. The service time for all gas stations is set as $30 \mathrm{~min}$, and the parameters of oil tank truck are shown in Table 4. Other parameters are set as shown in Table 5 with referring to the literatures [33-35].

Table 3. Demand Information of gas stations.

\begin{tabular}{|c|c|c|c|c|c|c|}
\hline $\begin{array}{l}\text { Demand } \\
\text { Point }\end{array}$ & $x$ Coordinate & $y$ Coordinate & $\begin{array}{c}\text { Maximum } \\
\text { Inventory }\left(\mathrm{m}^{3}\right)\end{array}$ & $\begin{array}{c}\text { Current } \\
\text { Inventory }\left(\mathrm{m}^{3}\right)\end{array}$ & $\begin{array}{c}\text { Minimum } \\
\text { Demand }\left(\mathrm{m}^{3}\right)\end{array}$ & $\begin{array}{l}\text { Consumption } \\
\text { Rate }\left(\mathrm{m}^{3} / \mathrm{min}\right)\end{array}$ \\
\hline 1 & 91 & 71 & 32 & 11.52598 & 11.52598 & 0.024012 \\
\hline 3 & 10 & 7 & 16 & 7.62968 & 7.62968 & 0.015895 \\
\hline 4 & 73 & 26 & 21 & 8.392063 & 8.392063 & 0.017483 \\
\hline 5 & 7 & 6 & 21 & 7.830946 & 7.830946 & 0.016314 \\
\hline 8 & 96 & 80 & 48 & 20.32358 & 20.32358 & 0.042341 \\
\hline 9 & 23 & 32 & 49 & 20.03141 & 20.03141 & 0.042982 \\
\hline 10 & 68 & 27 & 36 & 13.00829 & 13.00829 & 0.027101 \\
\hline 11 & 20 & 66 & 39 & 13.17007 & 13.17007 & 0.027438 \\
\hline 12 & 81 & 37 & 31 & 11.61286 & 11.61286 & 0.024193 \\
\hline 17 & 25 & 6 & 14 & 4.683246 & 4.683246 & 0.009757 \\
\hline 18 & 36 & 24 & 40 & 16.78833 & 16.78833 & 0.034976 \\
\hline 19 & 25 & 22 & 48 & 21.44084 & 21.44084 & 0.044668 \\
\hline
\end{tabular}


Table 4. The parameters of oil tank truck.

\begin{tabular}{cccc}
\hline Parameter & Parameter Value & Parameter & Parameter Value \\
\hline Outline dimension $(\mathrm{mm})$ & $12,350 \times 2500 \times 3850$ & Tank volume $\left(\mathrm{m}^{3}\right)$ & 51 \\
Total mass $(\mathrm{kg})$ & 40,000 & Rated load capacity $(\mathrm{kg})$ & 33,400 \\
The number of tires & 12 & Rated power $(\mathrm{kw})$ & 335 \\
Swept volume $(\mathrm{L})$ & 4.0 & Integrated fuel consumption $(\mathrm{L} / \mathrm{km})$ & 0.4 \\
\hline
\end{tabular}

Table 5. Model parameter settings.

\begin{tabular}{cc}
\hline Parameter & Parameter Value \\
\hline$M$ & $200 \mathrm{CNY} / \mathrm{d}$ \\
$h_{0}$ & $32 \mathrm{CNY} / \mathrm{t} \cdot \mathrm{d}$ \\
$h_{i}$ & $50 \mathrm{CNY} / \mathrm{t} \cdot \mathrm{d}$ \\
$C_{k}$ & $100 \mathrm{CNY} / \mathrm{d}$ \\
$b_{i}$ & $1000 \mathrm{CNY} / \mathrm{t}$ \\
$\mu_{1}$ & $30 \mathrm{CNY} / \mathrm{h}$ \\
$\mu_{2}$ & $40 \mathrm{CNY} / \mathrm{h}$ \\
$v$ & $20 \mathrm{~km} / \mathrm{h}$ \\
$\rho_{0}$ & $0.23 \mathrm{~L} / \mathrm{km}$ \\
$e_{0}$ & $2.83 \mathrm{~kg} / \mathrm{L}$ \\
$\rho^{*}$ & $0.45 \mathrm{~L} / \mathrm{km}$ \\
\hline
\end{tabular}

\subsubsection{Results with Different Carbon Tax Values}

We set the value of carbon $\operatorname{tax} C_{0}$ (unit: $\mathrm{CNY} / \mathrm{kg}$ ) from 0 to 25 in the model with referring to the literatures [5,36]. Each $C_{0}$ value is taken into the model to solve 10 times and the numerical value of the scheme with the optimal objective function is recorded, and then results can be obtained, as in Figures 2-4. Figure 2 is a line chart showing the changing trends of transportation costs, inventory costs, penalty costs, fixed costs, and carbon emission costs as carbon tax increases. It is possible to visually observe in detail the trend of each sub-cost changes as the carbon tax changes. Figure 3 is a stacked area chart showing the trend of total costs and each sub-cost changes as the carbon tax changes. The trends of total costs and carbon emissions change as carbon taxes increase, which are shown in Figure 4.

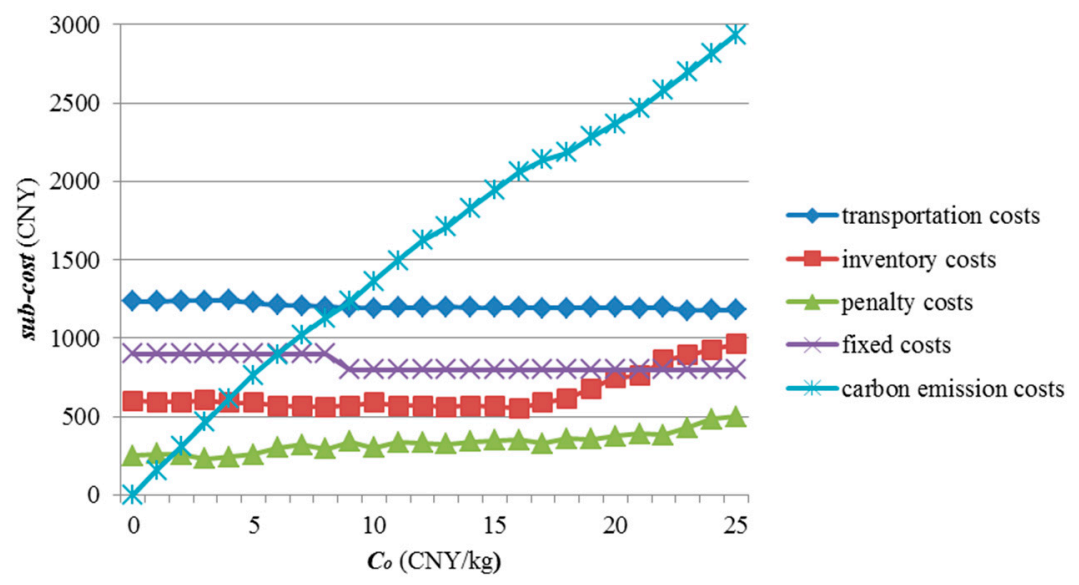

Figure 2. The line chart that shows the changing trends of each sub-cost as the carbon tax changes. 


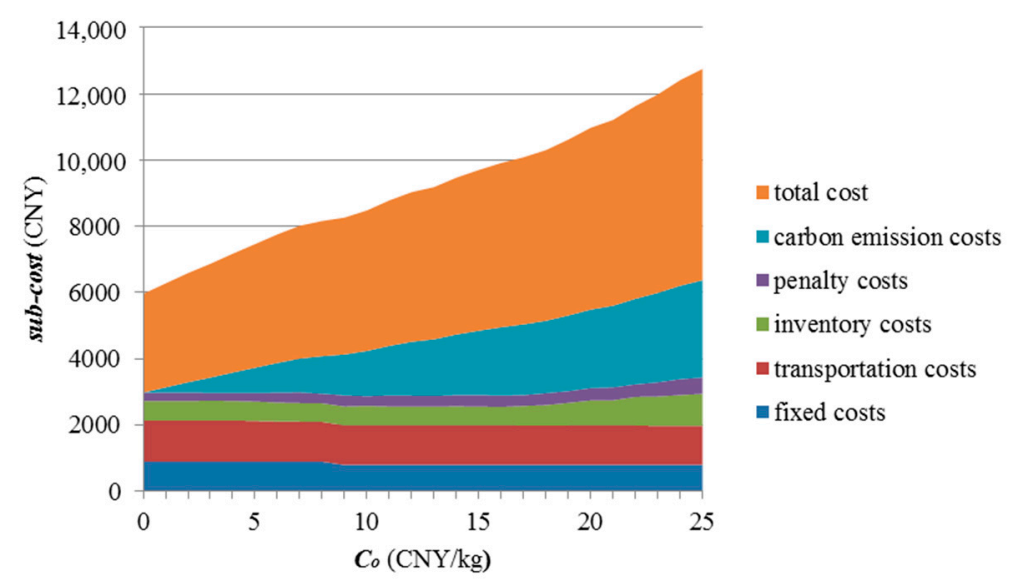

Figure 3. The stacked area chart that shows the changing trends of total cost and each sub-cost as the carbon tax changes.

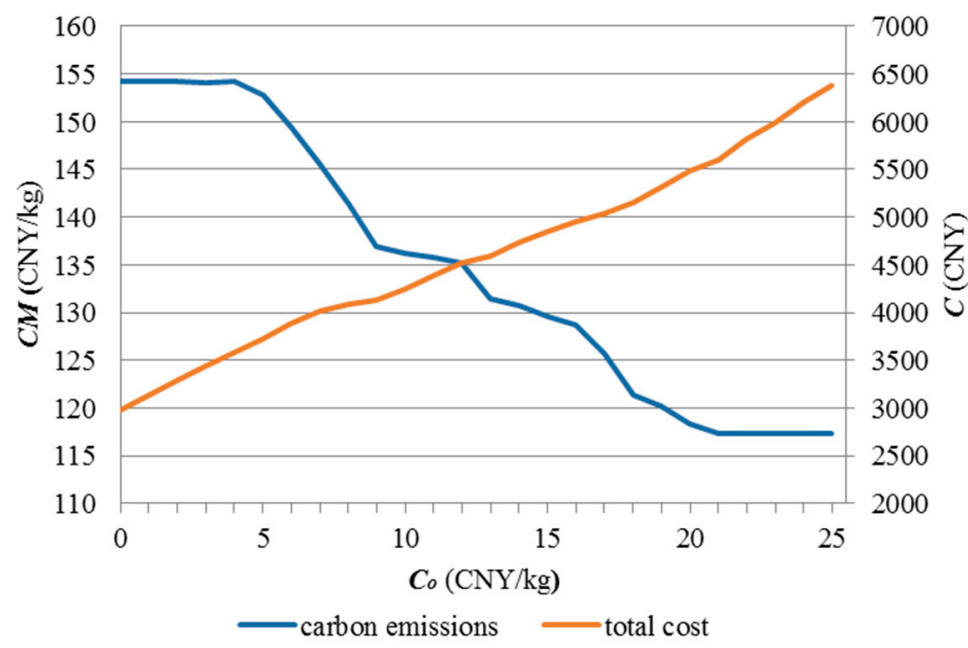

Figure 4. The line chart that shows the changing trends of total cost and carbon emissions as the carbon tax changes.

From the results in Figures 2-4, we can observe the following findings:

(1) All sub-costs in the distribution schemes have changed with the gradual increase of the carbon tax. The carbon emission costs, inventory costs, and penalty costs increase with the increase of carbon tax, of which the carbon emission costs change the most. However, the fixed costs and transportation costs decrease with the increase of carbon tax. According to Formula (2) and (10), it can be seen that both carbon emission costs and transportation costs are directly proportional to the transport distance. The model with the minimum total costs as the objective function will restrain the growth trend of carbon emission costs by optimizing the transport distance. At the same time, the reduction of the transport distance leads to the decrease of transportation costs. In addition, the Formula (10) shows that carbon emission costs are directly proportional to carbon emissions. In order to reduce the substantial increase in carbon emission costs, the model reduces the carbon emissions by optimizing the number of oil tank trucks, which also leads to a reduction in fixed costs.

(2) The proportion of each sub-cost in the total costs of distribution schemes has changed with the gradual increase of the carbon tax. The proportion of carbon emission costs in the total costs increases with the increase of the carbon tax, while the proportions of the remaining sub-costs in 
the total cost decrease with the increase of the carbon tax. The Formula (10) shows that carbon emission costs are directly proportional to carbon tax value, and the substantial increase in the carbon emission costs contributes to the increase in the total costs. Therefore, the proportion of carbon emission costs in total costs continues to increase. Although the inventory costs and penalty costs increase with the increase of carbon tax, the total costs increase more greatly, so the proportions of the sub-costs in the total costs are reduced.

(3) With the increase of carbon tax, the overall carbon emissions are on a downward trend, and the total costs are on the rise. From Figure 4, we can see that when the carbon tax changes in three different ranges, the carbon emissions will have different trends. When $C_{0} \in[0,4]$, carbon emissions remain unchanged because the carbon tax is too small at this time and the carbon emission costs account for a very small proportion of the total costs. When $C_{0} \in(4,21)$, there is continuous reduction in carbon emissions because the proportion of carbon emission costs in total costs increases gradually with the increase of carbon tax value. The model with the minimum cost as the objective function will continue to be optimized and the dramatic increase in costs is controlled by reducing carbon emissions. When $C_{0} \in[21,25]$, carbon emissions remain basically unchanged, the carbon tax value is very large at this time, and the carbon emission costs account for a large proportion of the total costs. The model with the minimum costs as the objective function has continuously optimized the carbon emissions to the minimum, so the carbon emissions remain unchanged. In summary, we can draw the conclusion that the carbon tax policy can reduce carbon emissions, but it will lead to the growth of distribution costs.

\subsubsection{Results with the Different Maximum Load Capacity of Oil Tank Trucks}

In this section, the carbon tax $C_{0}=12$ is taken as example to further analyze the impact of different maximum load capacity of oil tank trucks on carbon emissions and distribution schemes. The maximum load capacity of oil tank truck is set to 40,50 and $60\left(\mathrm{~m}^{3}\right)$, and then three groups of distribution schemes data are obtained respectively (each group is solved ten times, and the best schemes are selected), as shown in Table 6.

Table 6. Distribution schemes with the different maximum load capacity of oil tank trucks.

\begin{tabular}{|c|c|c|c|c|c|}
\hline \multirow{2}{*}{$\begin{array}{c}\text { Load } \\
\text { Capacity }\left(\mathrm{m}^{3}\right)\end{array}$} & \multirow{2}{*}{$\begin{array}{c}\text { The Number } \\
\text { of Truck }\end{array}$} & \multicolumn{2}{|c|}{ Distribution Scheme } & \multirow{2}{*}{$\begin{array}{l}\text { Total Costs } \\
\text { (CNY) }\end{array}$} & \multirow{2}{*}{$\begin{array}{c}\text { Carbon } \\
\text { Emissions (kg) }\end{array}$} \\
\hline & & $0-14-1-15-0$ & $0-8-16-0$ & & \\
\hline \multirow{4}{*}{40} & \multirow{4}{*}{8} & $0-12-2-0$ & $0-7-17-13-0$ & \multirow{4}{*}{5747.57} & \multirow{4}{*}{166.07} \\
\hline & & $0-6-3-5-0$ & $0-10-9-0$ & & \\
\hline & & $0-19-11-0$ & $0-4-18-0$ & & \\
\hline & & $0-12-14-2-0$ & $0-18-9-11-0$ & & \\
\hline \multirow[t]{2}{*}{50} & \multirow[t]{2}{*}{6} & $0-7-6-17-3-0$ & $0-1-8-16-0$ & \multirow[t]{2}{*}{4517.73} & \multirow[t]{2}{*}{135.24} \\
\hline & & $0-10-4-15-0$ & $0-19-13-5-0$ & & \\
\hline 60 & 5 & $\begin{array}{c}0-19-3-5-0 \\
0-14-11-13-0 \\
0-1-8-16-2-0\end{array}$ & $\begin{array}{c}0-6-9-18-17-0 \\
0-7-10-4-12-15-0\end{array}$ & 4076.22 & 125.02 \\
\hline
\end{tabular}

From the results in Table 6, we can observe the following findings:

(1) When the oil tank trucks with different maximum load capacity are selected for distribution, the number of trucks used in the distribution schemes will be changed. The delivery scheme needs to meet the minimum demand of each gas station to maintain the current inventory, and also to meet the potential demand time window of each gas station (the gas stations must be serviced before the current inventory is used up). Therefore, when the maximum load capacity of oil tank trucks is different, the model with the minimum costs as the objective function will choose different number of trucks. From Table 6, it can be seen that the greater the maximum load capacity of oil tank trucks, the smaller the number of trucks used. 
(2) When the oil tank trucks with different maximum load capacity are selected for distribution, the total costs and carbon emissions will be affected. As shown in Table 6, when the oil tank trucks with the larger load capacity are used to distribution, the total costs of the distribution scheme are smaller as well as carbon emissions are relatively smaller.

\subsection{Discussion and Analysis}

For the inventory routing problem in the distribution process of refined oil, the LCIRP model is proposed in this paper to aim at the combination optimization of inventory and distribution. By taking the minimum total costs including carbon emission costs as the objective function, the distribution scheme that takes into account both economic and environmental benefits can be obtained, thereby achieving "green and low-carbon" energy distribution. However, from Section 5.2.1, we can see that the total costs of the distribution scheme have increased significantly with the increase of the carbon tax, which shows that is necessary to pay a certain economic costs for the realization of green and low-carbon logistics transportation under the trend of global warming. Through the analysis in Section 5.2.2, we know that under the development environment of energy-saving and emission-reduction, energy transport enterprises can use the delivery trucks with the appropriate load capacity to alleviate the increase in the total costs caused by the increase of carbon emission costs.

Government environmental protection agencies can adopt carbon tax policies and emission-reduction incentive policies to guide and encourage energy transportation enterprises to carry out energy conservation and emission reduction. Firstly, what they should do is to formulate carbon tax policies suitable for economic development in different industries, and strengthen supervision and monitoring of carbon emissions, thus urging enterprises to raise awareness of green and low-carbon. Secondly, the government can formulate a series of emission reduction incentive policies based on the current economic development status in different industries. The enterprises that have taken the initiative to save energy and reduce emissions should be subsidized, which will alleviate their pressure on the increase of operating costs caused by the carbon tax policies. This paper finds that carbon emissions remain basically unchanged when $C_{0} \in[21,25]$ in Section 5.2.1. It means that the carbon tax policy has limitation to reduce carbon emissions. In this situation, the government may use other ways such as subsidies to reduce carbon emissions. Thirdly, the government may think about supporting and promoting the development of low-carbon equipment. Meanwhile, the low-carbon operation companies with greater influence in the industries should be rewarded to form a demonstration effect of the low-carbon economy. Finally, the green and low-carbon consumption preferences need to be guided from the consumer side, which means that a "national low-carbon" consumption concept is established from the source of market demand.

Energy transport enterprises can adopt a series of appropriate optimization measures to balance economic and environmental benefits. First, it might make sense to introduce carbon emissions into the optimization of inventory routing problems for energy distribution and choose an optimization distribution scheme that takes into account both emission reduction and costs. Second, some measures can be taken to alleviate the pressure of costs increase brought by carbon regulatory policies, such as optimizing inventory management costs, distribution batch and distribution volume, choosing the type of transport truck reasonably (in line with the requirements of road weight restriction), and so on. Third, energy transport enterprises should respond to the low-carbon policies of the government and its industry associations and actively adopt low-carbon operation mode and transport equipment.

\section{Conclusions}

Simple inventory control and transportation strategy are classic problems studied over a long period of time in operational research. There are ideal solution algorithms for the models corresponding to most practical problems. However, there is little research on the joint optimization of inventory and transportation in refined oil logistics, especially IRP from a low-carbon perspective. With the aggravation of global warming and environmental pollution, low-carbon and 
environmentally friendly economies have become the development trends for the whole world. In the secondary distribution logistics network of refined oil with the characteristics of small quantity and multiple batches, countless gas stations require a continuous supply of refined oil, but energy transportation is accompanied by a large amount of carbon emissions. Under the background of carbon tax and other carbon regulatory policies that have been continuously enacted by governments around the world, it is necessary to optimize the secondary distribution network of refined oil while taking into account both economic and environmental benefits. In this paper, the LCIRP model is designed for inventory routing problem in the distribution process of refined oil, and an improved adaptive genetic algorithm combined with greedy algorithm is introduced to solve the model. Moreover, the numerical experiments are used to verify the effectiveness of the algorithm. Then, a practical example is introduced for simulation, and the effectiveness of the model is verified. The experimental results prove that the carbon tax policies can effectively reduce the carbon emissions in the distribution network of refined oil on the premise of paying a certain economic costs. In addition, the impact of the maximum load capacity of oil tank trucks on the distribution scheme is also analyzed.

However, in the actual distribution environment, the uncertainty of many parameters will affect the output of LCIRP model and then affect the optimal distribution scheme. In this paper, we develop our study from the perspective of the carbon tax policies. Carbon-constrained methods have a very significant contribution to emission reduction, but the implementation of mandatory carbon-constraints is hardly recognized by enterprises. For future research work, we will further study the emission-reduction optimization of refined oil distribution under various policies such as carbon supervision and carbon subsidy.

Author Contributions: S.W. was mainly responsible for the writing of the full text. S.W. implemented the experiments with the guidance of F.T. S.W. and Y.S. built the models of the paper.

Acknowledgments: This work is supported by the National Natural Science Foundation of China (No. 71571023).

Conflicts of Interest: The authors declare no conflict of interest.

\section{References}

1. Zeng, Y.; Cai, Y.; Huang, G.; Dai, J. A review on optimization modeling of energy systems planning and ghg emission mitigation under uncertainty. Energies 2011, 4, 1624-1656. [CrossRef]

2. Min, L.; Shaoquan, N.; Ling, Z.; Qiang, H. Vehicle routing problem with time windows of petroleum products distribution based on order neighborhood system. Comput. Integr. Manuf. Syst. 2015, 21, 2158-2169.

3. Wang, S.; Tao, F.; Shi, Y. Optimization of location-routing problem for cold chain logistics considering carbon footprint. Int. J. Environ. Res. Public Health 2018, 15, 86. [CrossRef] [PubMed]

4. Wang, Y.; Zhou, Y.; Zhu, L.; Zhang, F.; Zhang, Y. Influencing factors and decoupling elasticity of China's transportation carbon emissions. Energies 2018, 11, 1157. [CrossRef]

5. Wang, S.; Tao, F.; Shi, Y.; Wen, H. Optimization of vehicle routing problem with time windows for cold chain logistics based on carbon tax. Sustainability 2017, 9, 694. [CrossRef]

6. Federgruen, A.; Zipkin, P. A combined vehicle routing and inventory allocation problem. Oper. Res. 1984, 32, 1019-1037. [CrossRef]

7. Golden, B.; Assad, A.; Dahl, R. Analysis of a large-scale vehicle routing problem with an inventory component. Large Scale Syst. 1984, 7, 181-190.

8. Avella, P.; Boccia, M.; Sforza, A. Solving a fuel delivery problem by heuristic and exact approaches. Eur. J. Oper. Res. 2004, 152, 170-179. [CrossRef]

9. Cornillier, F. A heuristic for the multi-period petrol station replenishment problem. Eur. J. Oper. Res. 2008, 191, 295-305. [CrossRef]

10. Cornillier, F.; Laporte, G.; Boctor, F.F.; Renaud, J. The petrol station replenishment problem with time windows. Comput. Oper. Res. 2009, 36, 919-935. [CrossRef]

11. Cornillier, F.; Boctor, F.; Renaud, J. Heuristics for the multi-depot petrol station replenishment problem with time windows. Eur. J. Oper. Res. 2012, 220, 361-369. [CrossRef] 
12. Dai, X.; Yao-Hua, Y.E.; Qin-Min, W.U.; Zhu, D.L. Interactively solving the vehicle routing problem for petroleum delivery. J. Syst. Eng. 2009, 24, 749-753.

13. Yi-Fei, M.A.; Sun, X.Y. Dispatching optimization model of second distribution of gasolin \& diesel oil and solution based on genetic algorithm. Oper. Res. Manag. Sci. 2010, 19, 73-78.

14. Boctor, F.F.; Renaud, J.; Cornillier, F. Trip packing in petrol stations replenishment. Omega 2011, 39, 86-98. [CrossRef]

15. Zhen, F. Multi-period vehicle routing problem with recurring dynamic time windows. In Proceedings of the IEEE International Conference on Service Systems and Service Management, Tianjin, China, 25-27 June 2011.

16. Popović, D.; Vidović, M.; Radivojević, G. Variable neighborhood search heuristic for the inventory routing problem in fuel delivery. Expert Syst. Appl. 2012, 39, 13390-13398. [CrossRef]

17. Wang, X.P.; Zhan, H.X.; Sun, Z.L.; Gao, Y. Route optimization for the refined oil multi-compartment distribution based on ant colony and tabu search hybrid algorithm. Syst. Eng. Theory Pract. 2017, 37, 3215-3226.

18. Tsai, W.H.; Shen, Y.S.; Lee, P.L.; Chen, H.C.; Kuo, L.; Huang, C.C. Integrating information about the cost of carbon through activity-based costing. J. Clean. Prod. 2012, 36, 102-111. [CrossRef]

19. Jabali, O.; Woensel, T.V.; Kok, A.G.D. Analysis of travel times and co 2 emissions in time-dependent vehicle routing. Prod. Oper. Manag. 2012, 21, 1060-1074. [CrossRef]

20. Elhedhli, S.; Merrick, R. Green supply chain network design to reduce carbon emissions. Transp. Res. Part D 2012, 17, 370-379. [CrossRef]

21. Wang, F.; Lai, X.; Shi, N. A multi-objective optimization for green supply chain network design. Decis. Support Syst. 2011, 51, 262-269. [CrossRef]

22. Tsai, W.H.; Lee, K.C.; Liu, J.Y.; Lin, H.L.; Chou, Y.W.; Lin, S.J. A mixed activity-based costing decision model for green airline fleet planning under the constraints of the european union emissions trading scheme. Energy 2012, 39, 218-226. [CrossRef]

23. Jaber, M.Y.; Glock, C.H.; Saadany, A.M.A.E. Supply chain coordination with emissions reduction incentives. Int. J. Prod. Res. 2013, 51, 69-82. [CrossRef]

24. Palak, G.; Ekşioğlu, S.D.; Geunes, J. Analyzing the impacts of carbon regulatory mechanisms on supplier and mode selection decisions: An application to a biofuel supply chain. Int. J. Prod. Econ. 2014, 154, $198-216$. [CrossRef]

25. Yuan, S.; Skinner, B.; Huang, S.; Liu, D. A new crossover approach for solving the multiple travelling salesmen problem using genetic algorithms. Eur. J. Oper. Res. 2013, 228, 72-82. [CrossRef]

26. Shima, T.; Rasmussen, S.J.; Sparks, A.G.; Passino, K.M. Multiple task assignments for cooperating uninhabited aerial vehicles using genetic algorithms. Comput. Oper. Res. 2006, 33, 3252-3269. [CrossRef]

27. Ying-Ying, Y.U.; Yan, C.; Tao-Ying, L.I. Improved genetic algorithm for solving tsp. Control Decis. 2014, 29, 1483-1488.

28. Liu, W.Y.; Lin, C.C.; Chiu, C.R.; Tsao, Y.S.; Wang, Q. Minimizing the carbon footprint for the time-dependent heterogeneous-fleet vehicle routing problem with alternative paths. Sustainability 2014, 6, 4658-4684. [CrossRef]

29. Vidal, T.; Crainic, T.G.; Gendreau, M.; Prins, C. A hybrid genetic algorithm with adaptive diversity management for a large class of vehicle routing problems with time-windows. Comput. Oper. Res. 2013, 40, 475-489. [CrossRef]

30. Srinivas, M.; Patnaik, L.M. Adaptive probabilities of crossover and mutation in genetic algorithms. IEEE Trans. Syst. Man Cybern. 2002, 24, 656-667. [CrossRef]

31. Dong, W.C.; Lee, Y.H.; Lee, T.Y.; Gen, M. An adaptive genetic algorithm for the time dependent inventory routing problem. J. Intell. Manuf. 2014, 25, 1025-1042.

32. Solomon, M.M. Algorithms for the vehicle routing and scheduling problems with time window constraints. Oper. Res. 1987, 35, 254-265. [CrossRef]

33. Mi, Z.; Meng, J.; Guan, D.; Shan, Y.; Song, M.; Wei, Y.M.; Liu, Z.; Hubacek, K. Chinese $\mathrm{CO}_{2}$ emission flows have reversed since the global financial crisis. Nat. Commun. 2017, 8, 1712. [CrossRef] [PubMed]

34. Mi, Z.; Meng, J.; Guan, D.; Shan, Y.; Liu, Z.; Wang, Y.; Feng, K.; Wei, Y.M. Pattern changes in determinants of chinese emissions. Environ. Res. Lett. 2017, 12, 074003. [CrossRef] 
35. Mi, Z.; Zhang, Y.; Guan, D.; Shan, Y.; Liu, Z.; Cong, R.; Yuan, X.C.; Wei, Y.M. Consumption-based emission accounting for chinese cities. Appl. Energy 2016, 184, 1073-1081. [CrossRef]

36. Mcausland, C.; Najjar, N. Carbon footprint taxes. Environ. Resour. Econ. 2015, 61, 37-70. [CrossRef]

(c)

(C) 2018 by the authors. Licensee MDPI, Basel, Switzerland. This article is an open access article distributed under the terms and conditions of the Creative Commons Attribution (CC BY) license (http:/ / creativecommons.org/licenses/by/4.0/). 